\title{
Ethnic Pluralism and Diversity Management in Sub Sahara Africa
}

\author{
Dr. Erasmus Kofi Appiah \\ University of the Witwatersrand
}

\begin{abstract}
The interplay of ethnic pluralism and diversity management is critical in the creation of an inclusive society. The benefit of an inclusive society is overwhelming, however, ethnicity within a diverse environment poses a significant challenge in the quest to achieve this feat. In this regard, instilling the sense of belongingness among members of the various ethnic groups within a society fuels inclusiveness. The mosaic of ethnic groups in sub-Sahara Africa underlines the entrenched diversity found within the region. This paper argues and demonstrates that the phenomenon of ethnic pluralism within sub-Sahara Africa (SSA) should form the bedrock of diversity management to ensure inclusion. Invalidating this argument this paper employs in-depth literature spanning ethnicity, diversity, and inclusion management. To this end, effective diversity management may be undergirded by the appreciation and recognition of ethnicity pluralism as one of its significant elements in ensuring inclusion.
\end{abstract}

Keywords: Appreciation; Belongingness; Inclusion; Interplay; Recognition; Uniqueness

\section{Introduction}

The foundation of African states cannot be divorced from its ethnic composition. This is evident in the assertion by Deng (1997) that building African nations without factoring in its ethnic realities is like erecting a structure on a weak foundation. In this regard, the numerous ethnic groups in sub-Sahara Africa forms an essential element in the management of diversity to ensure inclusion. Ethnicity is described in this article as a group of people who have the following common attributes which normally emanate from customary ancestry such as 
culture, heritage, language, religion as well as ideologies (Infomory 2011). Therefore, ethnicity remains an important element in SSA and its recognition and appreciation are critical for the creation of a vibrant socio-economic environment (Appiah, Arko-Acheamfour \& Ardeyeye 2018). On the other hand, pluralism is described as the benefit of diversity where autonomy is distributed among various groups in society (Encyclopedia Britannica 2008). More explicitly, pluralism supports the recognition and appreciation of the myriad of ethnic groups in society, enforcing the tenet of diversity management.

Turning our attention to diversity management, it is defined as the recognition and appreciation of individual or group uniqueness (Daya 2014), and the utilization of these unique characteristics to ensuring the needed inclusion (O’Mara \& Richter 2014 ) which translates into achieving a common goal. Subsequently, effective diversity management creates a vibrant and conducive society. This is evident in studies which indicates that diverse group are often innovative, multi-dimensional, and more importantly productive (Cox, 2001; Hubbard, 2004). Per the narration above, it is explicit that there is a link between ethnic pluralism and diversity management. To this end, SSA may enjoy the benefit of ethnic pluralism if efficient diversity management is entrenched. Therefore, the existence of ethnic pluralism is undergirded by effective diversity management.

Subsequent sections of this article are arranged in the following manner: a brief overview of the societal content under discussion is discussed, it is then followed by ethnic pluralism and diversity and inclusion management as well as its benefits. Further, a discussion section is presented which outlines the interplay of ethnic pluralism and diversity and inclusion management. Additionally, the need for ethic groups to acknowledge and appreciate other ethnic practices with understanding is highlighted. Finally, a conclusion section which synthesizes the entire article is presented to emphasize the need for efficient diversity management to obtain the benefit of ethnic pluralism.

\section{Brief Overview of Sub Sahara Africa (SSA)}

SSA is the area that lies beneath the Sahara Desert on the continent (United Nations, 2008). The region is very diverse with numerous ethnic groups which stretches across countries (Achebe 2000) and its presently made up of fifty four countries. Explaining further, SSA 
$2^{\text {nd }}$ International Conference on NEW TRENDS IN SOCIAL SCIENCES

consist of countries which are either fully or partially located below the Sahara (United Nations 2008). However, few countries which are geographically located in SSA are classified as members of the Arab world, they are Somalia, Djibouti, Comoros, and Mauritania (European Union, 2016). The ethnic groups normally cut across countries making it very important to ensure ethnic pluralism through efficient diversity management. For instance, the Hausa in Nigeria, Ghana, Cameroon to mention a few. In the same light the Yoruba in Nigeria and Benin, likewise the Igbo in Nigeria and Cameroon (Achebe, 2000). More importantly, the current wave of migration within the continent of Africa compounds ethnic diversity (Ratha \& Shaw 2007), making ethnic pluralism an essential aspect of social cohesion or inclusion. Inclusion in this regard may be achieved through effective diversity management.

\section{Overview of Ethnic Pluralism}

Ethnic pluralism is a concept pivoted on the preservation and mutual respect for differences within a region (Bar-On 2001; McCulloch 2006). In placing ethnic pluralism within the context of diversity, it will be worthwhile to discuss ethnicity and then juxtapose it to diversity management. The globalized state of communication, technology and commerce give rise to the interaction of a plethora of ethnic groupings. Given the fluidity and the advanced nature of this phenomenon, ethnic pluralism is perhaps more entrenched in the $21^{\text {st }}$ century than ever in modern history. This is evident in the appreciation of diversity and inclusion through the lens of ethnicity in SSA (Appiah, Arko- Achemfour \& Adeyeye 2018), making its evaluation very critical.

As mentioned earlier, ethnicity is described as a group of individuals who share the same heritage, language, culture, religion, and common ancestry (Cornell \& Hartmann, 2007)). There are three main types of ethnicity which highlight its main characteristics. They are primordial epiphenomenon, situational and subjective phenomenon of ethnicity. Primordial ethnicity is derived from birth and its unchangeable (Geertz, 1963; Isaacs, 1975; Stack, 1986). The other forms of ethnicity are not cast in stone, it evolves with time. Epiphenomenon ethnicity deals with the phenomenon where an economy is built on inequality and exploitation (Hechter, 1978), this situation force individuals to identify and belong to groups who have similar social status. Further, situational ethnicity is created when an individual decides to be part of an ethnic group due to envisioned benefits (Nagata, 1974; Okamura, 1981), this situation 
may occur when members of society feel alienated and tend to gravitate towards the stronger groups in the society. More fluid nature of ethnicity is the subjective phenomenon which is a continuous process and thrives through negotiation in an individual's life (Herzog, 1984; Smith, 1984). Each aspect of ethnicity connotes differences and entrench diversity which needs to be recognized as a major element in the quest to attain inclusion.

Giving the diverse nature of SSA, coupled with the fluidity of borders in the region as well as the increase in intra-migration (Appiah \& Adeyeye 2020), ethnic pluralism has become significant and perhaps accounts for the sense of belonging in the society. The concepts of ethnic pluralism and diversity management have a lot in common since both are driven by differences.

\section{Overview of diversity management}

Diversity management has become more relevant in recent time due to globalization and regional integration. Its importance has been highlighted by both scholars and practitioners such as Cunningham (2007), Phillips, Mannix, Neale and Gruenfeld (2004) who assert that efficient management of diversity produces quality decisions. Notable of these assertions are “diversity makes business sense” (Mor Barak 2015:8). Efficient diversity management ensures an inclusive society which creates a sense of belonging. The mosaic of ethnic groups and its associated complexities in SSA, however, offers a competitive advantage per the benefits espoused by scholars and practitioners.

Although Africa is noted for its plethora of ethnic groupings, studies in this regard lag, in other words, SSA has not been featured in the body of literature as compared to other regions. (April \& Blass, 2010; Roberson, 2006; Pelled, Ledford \& Mohrman 1999). This has led to the African content been characterised by deep uncertainty (Munene 1991; Ugwuegbu 2001; Zoogah \& Nkomo 2012), making it necessary to investigate SSA into much detail. To buttress the point of uncertainty, a study conducted by Kaggwa, Dikgale, Zamudio and Haji (2013) confirmed that diversity management is at its embryonic stage in Africa, however, numerous nations on the continent are signatories to United Nations conventions in this respect. It may therefore be suitable to incorporate the concept of diversity management into ethnic pluralism to ensure 
$2^{\text {nd }}$ International Conference on NEW TRENDS IN SOCIAL SCIENCES

belongingness and reduce the uncertainty which has plagued the continent to the barest minimum.

\section{The Intermesh of Ethnic Pluralism and Diversity Management}

The narration above depicts clear similarities between ethnic pluralism and diversity management. The underlining factor is differences found among groups or individuals, which is upheld by both concepts. Ethnic pluralism upholds the preservation and respect for differences while diversity management is predicated on the appreciation and recognition of differences. In both instances, the sense of belonging which ensures inclusion drives the concepts. Therefore, ethnic pluralism drives diversity management and perhaps the reverse is true. In this regard, efficient diversity management may be undergirded by ethnic pluralism.

In conclusion, the efficient management of diversity through the prism of ethnic pluralism will reduce the uncertainty on the African content and for that matter SSA. Further, this approach may be a panacea to the numerous ethnic conflicts on the continent since the lack of belongingness by various ethnic groups may be the driving force. Additionally, it may reduce the complexities associated with the increase in intra-migration in Africa (Adepoju 2008). To this end, the two concepts under discussion can be summed up in one sentence, that is: we preserve what we appreciate and respect what we recognize. This cements the link between ethnic pluralism and diversity management.

\section{Reference}

Achebe, C. (2000). Home and exile. US: Oxford University Press.: 0-195-1306-7

Adepoju, A. (2008). Migration in Sub-Saharan Africa.: Uppsala Nordiska Afrikainstitutet.

Appiah, E.K., \& Adeyeye, O. P (2020). The Impact of Migration on Trade in Sub-Sahara Africa Diversity and Inclusion Perspective. The International Journal of Organizational Diversity. 20(2). https://doi.org/10.18848/2328-6261/CGP. 
$2^{\text {nd }}$ International Conference on NEW TRENDS IN SOCIAL SCIENCES 29-31 October, 2020

Appiah, E. K., Arko-Achemfuor, A., \& Adeyeye, O. P. (2018). Appreciation of diversity and inclusion in Sub-Sahara Africa: The socioeconomic implications. Cogent Social Sciences, 4(1), 1521058. https://doi.org/10.1080/23311886.2018.1521058.

April, K., \& Blass E. (2010). Measuring diversity practices and developing inclusion. Dimensions, 1(1): 56-66.

Bar-On, T. (2001) The Ambiguities of the Nouvelle Droite, 1968-1999, The European Legacy, 6:3, 333-351, DOI: 10.1080/10848770120051349.

Cornell, S., \& Hartmann, D. (2007). Ethnicity and Race: Making Identities in a Changing World. Thousand Oaks: Pine Forge Press.

Cox, T. (2001) Creating the Multicultural Organization. San Francisco, CA: Jossey-Bass.

Cunningham, G.B. (2007). Diversity in sport organizations. Scottsdale: Holcomb-Hathaway.

Daya, P. (2014). Diversity and inclusion in an emerging market context. Equality, Diversity, and Inclusion: An International Journal, 33(30), 293-308. doi:10.1108/ EDI-10-2012-0087

Deng, F.M. (1997). Ethnicity: An African Predicament. URL: https://www.brookings.edu/articles/ethnicity-an-african-predicament. Accessed 15/08/2020.

Encyclopaedia Britannica (2008). Pluralism. URL: https://www.britannica.com/topic/pluralism-politics. Accessed 15/08/2020.

European Union. (2016). League of Arab States (LAS). European external action service. URL: http://eueuropaeeas.fpfis.slb.ec.europa. eu:8084/generic-warning-system-taxonomy/404/ 7933/league-arab-state s-las_en. Accessed 15/08/2020.

Geertz, C. (1963). The integrative revolution: Primordial sentiments and civil politics in the new states. In C. Geertz (Ed.), Old societies and new states (pp. 105-115). New York: Free Press

Hechter, M. (1978). Group formation and the cultural division of labour. American Journal of Sociology, 84, 293-318. doi:10.1086/226785 
$2^{\text {nd }}$ International Conference on NEW TRENDS IN SOCIAL SCIENCES 29-31 October, 2020

Herzog, H. (1984). "Ethnicity as a product of political negotiation: The case of Israel. Ethnic and Racial Studies, 7, 517-533. doi:10.1080/01419870.1984.9993465

Infomory (2011). What is Ethnicity? URL: http://infomory.com/what-is/what-is-ethnicity. Accessed 15/08/2020.

Isaacs, H. (1975). Basic group identity: The idols of the tribe. In N. Glazer \& D. P. Moynihan (Eds.), Ethnicity: Theory and experience (pp. 29-52). Cambridge, MA: Harvard University Press

McCulloch, T. (2006). The Nouvelle Droite in the 1980s and 1990s: Ideology and Entryism, the Relationship with the Front National. Fr Polit 4, 158-178. https://doi.org/10.1057/palgrave.fp.8200099

Mor Barak, M.E. (2015). Inclusion is the key to diversity management, but what is inclusion? Human Service Organizations: Management, Leadership and Governance, 39 (2): 83-88, DOI: 10.1080/23303131.2015.1035599.

Munene, J. C. (1991). Organizational environment in Africa: A factor analysis of critical incidents. Human Relations, 44 (5): 439-458.

Nagata, J. (1974). What is a malay? Situational selection of ethnic identity in a plural society. American Ethnologist, 1, 331-350. doi:10.1525/ae.1974.1.2.02a00080

Okamura, J. (1981). Situational ethnicity. Ethnic and Racial Studies, 4, 452-465. doi:10.1080/01419870.1981.9993351

O’Mara., J., \& Richter, A. (2014). Global diversity and inclusion benchmarks: Standards for organizations around the world. The Diversity Collegium. URL: http://diversitycollegium.org/ GDIB_2014_Standard_US_Letter_Version.pdf. Accessed 15/08/2020.

Pelled, L.H., Ledford, G.E. \& Mohrman, S.A. (1999). Demographic dissimilarity and workplace inclusion. Journal of Management Studies, 36 (7): 0022-2380

Phillips, K., Mannix, E., Neale, M. \& Gruenfeld, D. (2004). Diverse groups and information sharing: The effect of congruent ties. Journal of Experimental Social Psychology, 40: 497-510. 
$2^{\text {nd }}$ International Conference on NEW TRENDS IN SOCIAL SCIENCES 29-31 October, 2020

Ratha D \& Shaw, W. (2007). South -South Migration and Remittances (No. 12). World Bank Publication.

Roberson, Q.M. (2006). Disentangling the meanings of diversity and inclusion in organization. Group and Organization Management, 31(2): 212-236.

Smith, S. (1984). Negotiating ethnicity in an uncertain environment. Ethnic and Racial Studies, 7, 360-373. doi:10.1080/01419870.1984.9993450

Stack, J. F. (ed). (1986). The primordial challenge. Westport, CT: Greenwood Press.

Ugwuegbu, D.C.E. (2001). The psychology of management in African organizations. Westport: Quorum.

United Nations. (2008). Composition of macro geographical (continental) regions, geographical subregions, and selected economic and other groupings. URL: http://mil lenniumindicators.un.org/unsd/methods/m49/ m49regin.htm. Access 15/08/2020.

Zoogah, D. B. \& Nkomo, S. (2012). Management research in Africa: Past, present, and future. In Lituchy, T.R., Punnett, B.J. \& Puplampu, B.B. (Eds.), Management in Africa: Macro and Micro Perspectives. New York: Routledge. 9-31. 